\title{
A comparative study on long term stability of self-healing epoxy coating with different inorganic nanotubes as healing agent reservoirs
}

\author{
P. P. Vijayan ${ }^{1}$, Y. Mohamed Hany El-Gawady ${ }^{1}$, M. Ali S A Al-Maadeed ${ }^{1,2}$ \\ ${ }^{1}$ Center for Advanced Materials, Qatar University, P.O. Box 2713, Doha, Qatar \\ ${ }^{2}$ Materials Science and Technology Program, Qatar University, P.O. Box 2713, Doha, Qatar
}

Received 14 March 2017; accepted in revised form 29 May 2017

\begin{abstract}
Self-healing epoxy coatings were prepared with different nanotubes as reservoirs for epoxy monomer (healing agent). The nanotubes selected for the current study were $\mathrm{TiO}_{2}$ nanotubes with two different tube diameter (TNT1 and TNT2) and naturally occurring hallyosite nanotubes (HNT). These self-healing coatings were subjected to accelerated weathering exposure. The weathering stability of the coatings were observed. The surface morphology, chemical changes and surface roughness were studied as a function of weathering exposure period. These studies confirmed that the long term stability of the coatings highly depend on the nanotube parameters such as nature, surface area and diameter. It was found that the photocatalytic degradation of epoxy matrix with $\mathrm{TiO}_{2}$ nanotubes was prominent in TNT1 filled coating compared with their TNT2 variant. The higher possibility of exposure of epoxy monomer encapsulated inside both HNT and TNT2 facilitated the cure reaction with UV light to create new chains during weathering.
\end{abstract}

Keywords: coatings, $\mathrm{TiO}_{2}$ nanotubes, hallyosite nanotubes, self-healing, weathering studies

\section{Introduction}

The modern world is facing serious concerns due to the corrosion of metal structures. To address this issue, different approaches were introduced by scientists $[1,2]$. Among them, polymer coatings are found to be an effective protective strategy for metal surfaces. Inorganic nanoparticles like nanoclay [3-5], nano iron oxide [6], nanosilica [7, 8], nano zinc oxide $(\mathrm{ZnO})$ $[9,10]$, nano aluminum phosphate [11] and carbon nanofillers like graphene [12, 13], carbon black [13], multi-wall carbon nanotube (MWCNT) [13] etc. filled polymer coatings further increase the protection ability. These fillers can act as multifunctional components in polymer coatings. These fillers are effective in enhancing the corrosion resistance, barrier properties and adhesion of the polymer coating. Among them, nano sized zinc oxide ( $\mathrm{ZnO})$ and carbon black were effectively used to block the coating from UV irradiation $[9,14]$. These nanofillers act as UV absorbers and prevent degradation of epoxy resin. Recently, the technologies involving the use selfhealing polymer coatings are proved to increase the life span of the metal substrates. The key component of self-healing coating is reservoirs for the storage and release of healing agents or corrosion inhibitors [15-19]. The loading of healing agents inside small diameters are getting much attention these days. Porous or tubular forms of inorganic particles such as mesoporous silica [20, 21], $\mathrm{TiO}_{2}$ nanotube [22], hollow $\mathrm{TiO}_{2}$ spheres [23], hollow porous $\mathrm{Mn}_{2} \mathrm{O}_{3}$ microsphere [24] etc. are used as reservoirs for corrosion inhibitors or healing agents.

The self-healing ability of $\mathrm{TiO}_{2}$ and hallyosite nanotubes were studied and previously reported $[25,26]$.

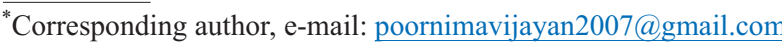
(C) BME-PT 
In such systems, epoxy monomer were loaded inside the tubular cavity of $\mathrm{TiO}_{2}$ nanotube or hallyosite. Thus loaded nanotubes were incorporated along with amine curing agent immobilized in mesoporous silica into epoxy coating to make it dual self-healing system. It was proved that the mechanism of self-healing in such dual systems depend on: (1) the release of the epoxy from the nanotubes into the scratch and (2) its successive crosslinking upon contact with the immobilized amine in mesoporous silica.

In the current research, the long term stability of such self-healing epoxy coatings were studied. $\mathrm{TiO}_{2}$ nanotubes with two different tube diameters and Hallyosite nanotubes are used as epoxy monomer reservoirs in the coating. Initially, corrosion resistance of the coatings and self-healing ability were compared using electrochemical impedance spectroscopic (EIS) analysis. Then, the coatings were exposed to accelerated weathering test. The exposed coatings were further subjected to detailed studies including morphology, Fourier transform infrared spectroscopy (FTIR) and surface roughness. A comparative study on weathering stability were carried out based on nanotube parameters such as surface area, nanotube diameter and nature of the material.

\section{Experimental}

\subsection{Materials}

$\mathrm{TiO}_{2}$ (anatase) nanopowder (5430MR) with a particle size of $15 \mathrm{~nm}$ supplied by Nanostructured \& Amorphous Materials, Inc., Houston, USA and $\mathrm{TiO}_{2}$ (anatase) powder (232033) with an average particle size of $120 \mathrm{~nm}$ supplied by Sigma-Aldrich were used as the precursor for $\mathrm{TiO}_{2}$ nanotubes. Halloysite (HNT) clay mineral (685445), hydrochloric acid $(\mathrm{HCl})$, ethanol and sodium hydroxide pellets were supplied by Sigma-Aldrich. Poly(ethylene glycol)-blockpoly(propylene glycol)-block-poly(ethylene glycol) (EO20PO70EO20) (PEG-PPG-PEG, Pluronic ${ }^{\circledR}$ $\mathrm{P}-123)$ with an average Mn-5,800 supplied by SigmaAldrich was used as template for the synthesis of mesoporous silica. Tetraethyl orthosilicate (TEOS) (reagent grade 98\%) from Sigma-Aldrich was used as silica source. Epon 826, Epon 815C and amine curing agent (Epikure 3223) were purchased from MillerStephenson Chemical Co, USA. Epon $815 \mathrm{C}$ is a diluted (with butyl glycidyl ether) form of Epon 826. Polished carbon steels were used as substrate for coating.

\subsection{Preparation methods}

Hydrothermal method was used to synthesize $\mathrm{TiO}_{2}$ nanotubes [27]. $1.2 \mathrm{~g}$ of $\mathrm{TiO}_{2}$ (anatase) nanopowder was treated with $20 \mathrm{~mL}$ of $10 \mathrm{~N} \mathrm{NaOH}$ solution in a Teflon beaker and stirred vigorously for $15 \mathrm{~min}$. The mixture was then transferred into a Teflon lined autoclave and heated in a preheated oven at $130^{\circ} \mathrm{C}$ for $10 \mathrm{hr}$. The obtained precipitate was washed with distilled water. The washed precipitate was dipped in $0.1 \mathrm{M} \mathrm{HCl}$ solution for $30 \mathrm{~min}$ and washed again with $\mathrm{HCl}$ solution and distilled water until the $\mathrm{pH}$ of the solution became 7 .

Finally, the synthesized powder was dried. The similar procedure was repeated by using $\mathrm{TiO}_{2}$ (anatase) powder as precursor and extending the time in hydrothermal reaction to $14 \mathrm{~h}$. It was found that the size scale of the precursor and the time for hydrothermal reaction controls the dimension of the produced $\mathrm{TiO}_{2}$ nanotube. The $\mathrm{TiO}_{2}$ nanotubes obtained from $\mathrm{TiO}_{2}$ (anatase) nanopowder and $\mathrm{TiO}_{2}$ (anatase) powder are abbreviated as TNT1 and TNT2.

SBA-15 mesoporous silica was synthesized using the amphiphilic triblock copolymer poly(ethylene glycol)-block-poly(propylene glycol)-block-poly(ethylene glycol) (EO20PO70EO20) as described in ref [28]. Thus prepared mesoporous silica was incubated with excess of Epikure 3223 for $24 \mathrm{~h}$ at $25^{\circ} \mathrm{C}$ using medium shaking rate in order to immobilize the amine molecules in pores of SBA-15.

Epoxy pre-polymer were encapsulated into different nanotubes using the following procedure. Epon $815 \mathrm{C} / 15 \mathrm{phr}$ nanotube solution was prepared by using a magnetic stirrer for $30 \mathrm{~min}$ at $1000 \mathrm{rpm}$. The homogenous solution subjected to repeated vacuum using vacuum jar for a time period of $6 \mathrm{~h}$ to complete the insertion of epoxy inside the nanotubes. The air trapped inside the tube lumen is replaced by the epoxy pre-polymer during the process.

To prepare the coating solution, encapsulated Epon $815 \mathrm{C} / 15 \mathrm{phr}$ nanotube mixture was diluted with Epon 826 resulting in epoxy/7.5 phr nanotube mixture. Then, $0.8 \mathrm{phr}$ amine immobilized mesoporous silica was mixed with the above solution via sonication followed by the addition of $10.9 \mathrm{phr}$ amine curing agent. Thus obtained homogeneous mixture was coated on one side of the carbon steel with an average thickness of $300 \mu \mathrm{m}$. The coating was cured for $24 \mathrm{~h}$. The control epoxy coating was prepared without nanotube and mesoporus silica. 
The morphology of the synthesized nanomaterials were studied using scanning electron microscopic (SEM) and transmission electron microscopic (TEM) techniques. Nova NanoSEM field emission Scanning electron microscopy with an accelerating voltage of $5.0 \mathrm{kV}$ was used. TEM study was carried out on a FEI TECNAI GF20 S-TWIN electron microscopy instrument. Brunauer-Emmett-Teller (BET) surface area analysis of the nanomaterials were performed with Micromeritics Chemisorb 2750 pulse chemisorption system. Sample mass was around $0.04 \mathrm{~g}$. The sample was degassed in presence of pure nitrogen for $30-45 \mathrm{~min}$ at $200^{\circ} \mathrm{C}$ prior to analysis. BET adsorption/desorption isotherm was determined by nitrogen sorption from a mixture of Helium $(70 \%) / \mathrm{Ni}-$ trogen $(30 \%)$ gas at the temperature of liquid nitrogen (77 K).

\subsection{Characterisation techniques}

Electrochemical impedance spectroscopic (EIS) studies of the coatings were carried out using Gamry Reference 600 Potentiostat/Galvanostat/ZRA. The reference electrode used was $\mathrm{Ag} / \mathrm{AgCl}$ electrode and a stainless steel counter electrode arranged parallel to the exposed sample to complete the cell. A $3.5 \mathrm{wt} \%$ $\mathrm{NaCl}$ aqueous solution was used as the electrolyte solution inside the cell. The sample was in touch with the electrolyte solution. The measurements were carried at ambient temperature. EIS measurements were carried out at in the frequency range $0.01-100000 \mathrm{~Hz}$. Accelerated weathering test was done by using QUV chamber (QUV-Spray Model) by following ASTM
G154. The cycle consists of $8 \mathrm{~h}$ of UV $(\lambda=340 \mathrm{~nm})$ radiation at $60^{\circ} \mathrm{C}$ and $4 \mathrm{~h}$ of condensation at $50^{\circ} \mathrm{C}$. The irradiation intensity was $0.89 \mathrm{~W} \cdot \mathrm{m}^{-2}$. The coating panels were exposed for different time interval up to 45 days. Benchtop scanning electron microscopy (JCM 6000, Jeol) and Leica DCM8 was used to observe the weathering exposed coating. Fourier transform infrared spectroscopic (FTIR) studies of the coating samples were carried out from 4000$600 \mathrm{~cm}^{-1}$ in FT-IR Frontier (PerkinElmer) instrument. Surface roughness of the coating samples were evaluated using profilometer (Leica DCM8 system).

\section{Results and discussions}

\subsection{Characterization of nanotubes}

The characteristic parameters of the synthesized $\mathrm{TiO}_{2}$ nanotubes and naturally occurring HNT are shown in Table 1. TNT1 has the highest and HNT has the lowest surface areas among the nanotubes. HNT are seen as double walled tubes with highest tube diameter. TNT1 has the least tube diameter among them. The observed average difference in the tube diameter of TNT1 and TNT2 is $8.5 \mathrm{~nm}$. How these parameters affect the self-healing ability and weathering stability of the coatings will be discussed in coming section.

\subsection{Electrochemical impedance spectroscopic (EIS) analysis}

Initially, the role of different nanotubes on corrosion resistance of the coating was estimated using EIS analysis. Bode and Nyquist plots for epoxy, epoxy/

Table 1. The characteristic parameters of the synthesized $\mathrm{TiO}_{2}$ nanotubes and naturally occurring halloysite

\begin{tabular}{|c|c|c|c|c|}
\hline \multirow{2}{*}{ Nanotubes } & \multicolumn{2}{|c|}{ Morphology } & \multirow{2}{*}{$\begin{array}{l}\text { BET surface area } \\
\qquad\left[\mathrm{m}^{2} / \mathrm{g}\right]\end{array}$} & \multirow{2}{*}{$\begin{array}{l}\text { Average pore diameter from TEM } \\
\qquad[\mathrm{nm}]\end{array}$} \\
\hline & TEM & SEM & & \\
\hline TNT1 & & & 200.29 & 1.5 \\
\hline TNT2 & & & 173.93 & 10 \\
\hline HNT & & & 45.31 & $\begin{array}{l}\text { Outer tube diameter }-75 \\
\text { Inner tube diameter }-22\end{array}$ \\
\hline
\end{tabular}



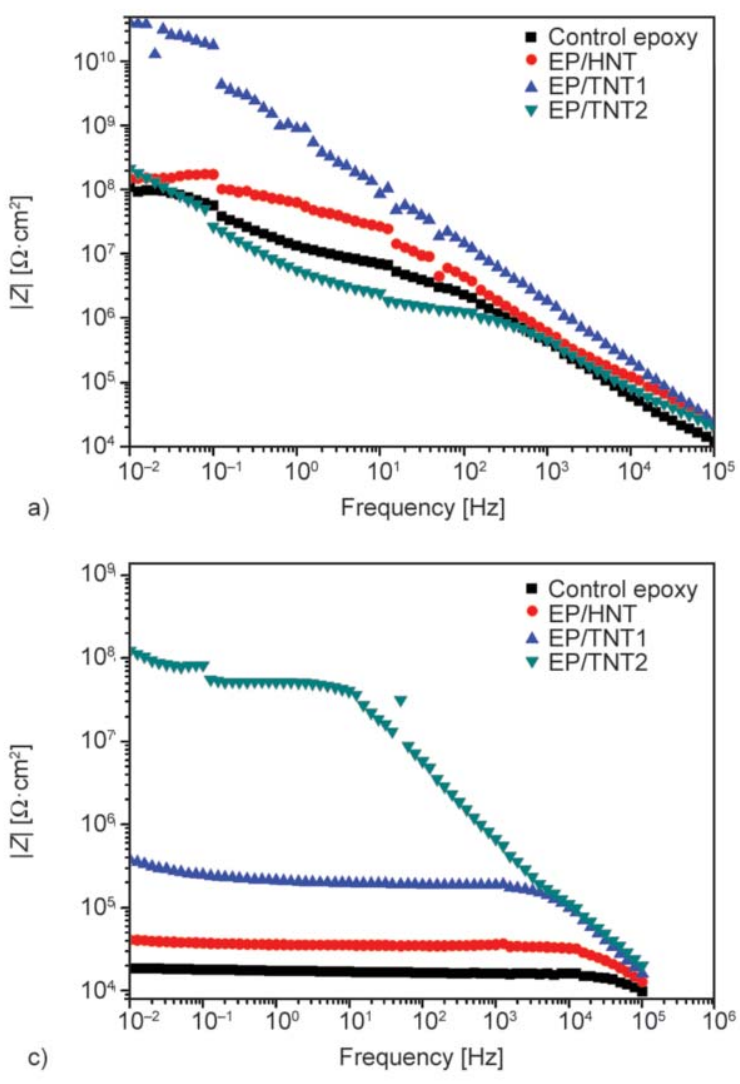
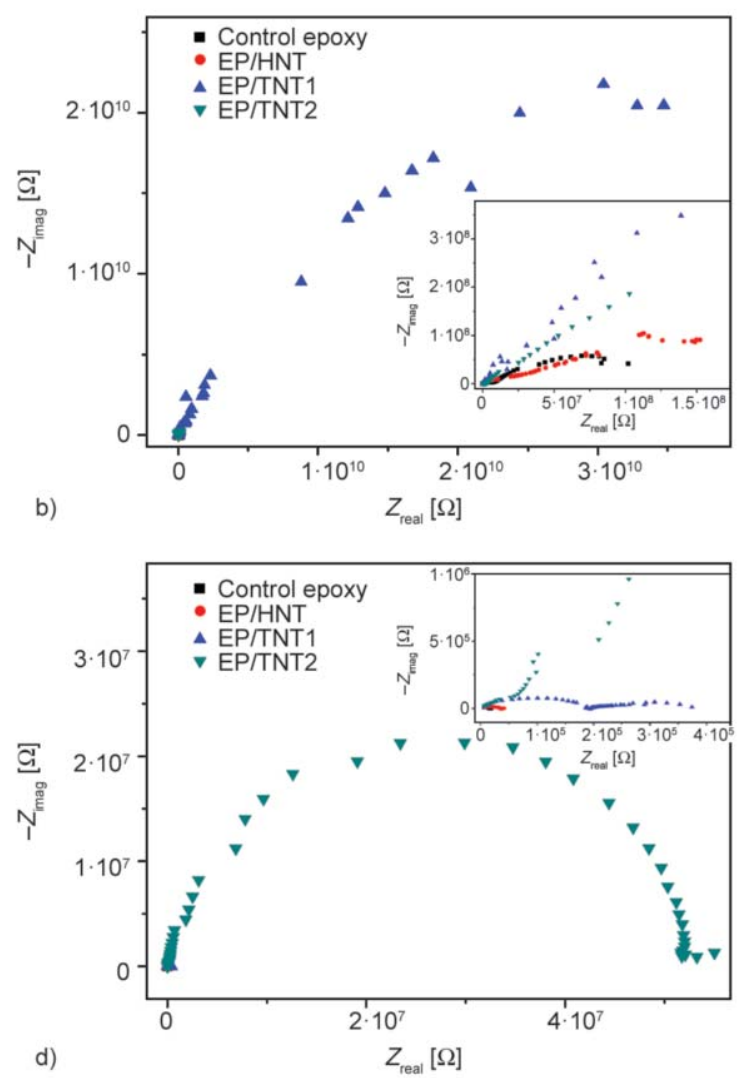

Figure 1. a) EIS Bode diagram and b) Nyquist plots for coatings, c) EIS Bode diagram and d) Nyquist plots for scratched coatings after $96 \mathrm{~h}$ of immersion in $3.5 \mathrm{wt} \% \mathrm{NaCl}$ solution

HNT, epoxy/TNT1 and epoxy/TNT2 coatings are shown in Figure 1a and 1b. The corrosion resistance of the coatings represents the impedance modulus $|Z|$ at the low-frequency $(0.01 \mathrm{~Hz})$. From Figure 1a, it can be evident that the presence of the three type of nanotubes enhanced the low frequency impedance value. However, $\mathrm{TiO}_{2}$ nanotube with higher surface area and lower tube diameter (TNT1) is superior among the other used nanotubes to enhance the corrosion resistance. The ability of different nanotubes loaded with epoxy monomer on self-healing ability of scratched epoxy coating were also compared using EIS studies. Figure 1c shows Bode plots for scratched coatings after $96 \mathrm{~h}$ of immersion in $\mathrm{NaCl}$ solution. It can be seen that the control coating completely failed to protect the metal beneath it after an immersion of $96 \mathrm{~h}$. The percentage recovery of the low frequency impedance with respect to control coating are 30.98, 64.16 and $105 \%$ for EP/HNT, EP/TNT1 and EP/ TNT2 respectively. The maximum recovery of the corrosion resistance is achieved by coating containing TNT2 ie. $\mathrm{TiO}_{2}$ nanotube with higher tube diameter. The low frequency impedance behvior of EP/ TNT2 coating is comparable with that of previously reported Tung oil encapsulated urea-formaldehyde shell based epoxy self-healing coating [29]. The selfhealing performance of coating with $\mathrm{TiO}_{2}$ nanotubes is higher than the Halloysite nanotubes irrespective of the tube diameter. Figure 1d shows the Nyquist plots for scratched coatings after $96 \mathrm{~h}$ of immersion. The highest radius semi-circles was shown by coating with TNT2 indicates its efficiency to recover anticorrosive properties compared to other coatings.

\subsection{Morphological studies of weathering samples}

Figure 2 shows the SEM images of self-healing coatings with different nanotubes. The surface of exposed control epoxy coating shows void formation and the voids are enlarged upon increasing the exposure time. In addition to the voids, visible cracks are formed on the surface of control epoxy coating (especially after 30 days of exposure). Thus formed cracks allow the penetration of water through the coating into the metal substrate. However, in nanotube incorporated epoxy coating the weathering exposure resulted in entirely different morphology when compared with control coating. SEM images of composite coatings showed the deposition of degraded products on the coating surface. The presence of voids or cracks are 


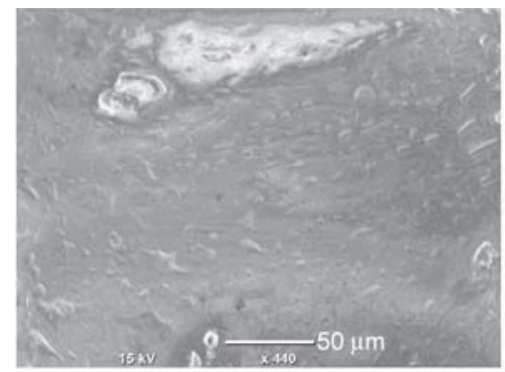

a)

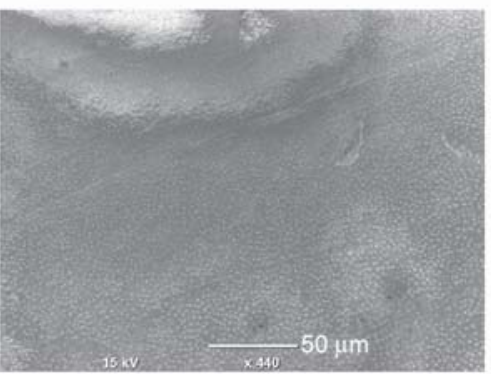

d)

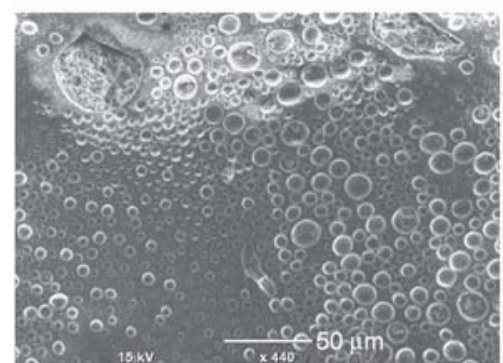

g)

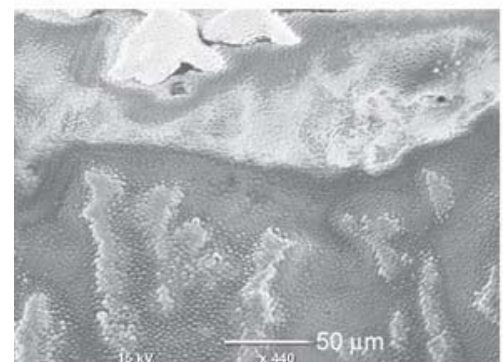

j)

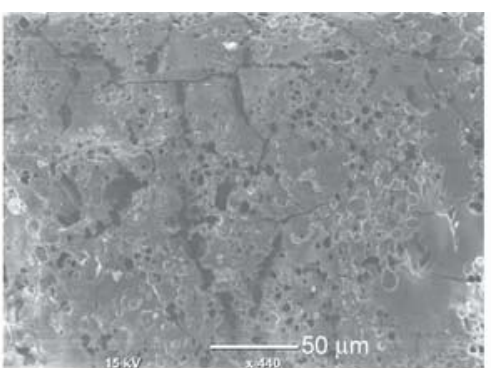

b)

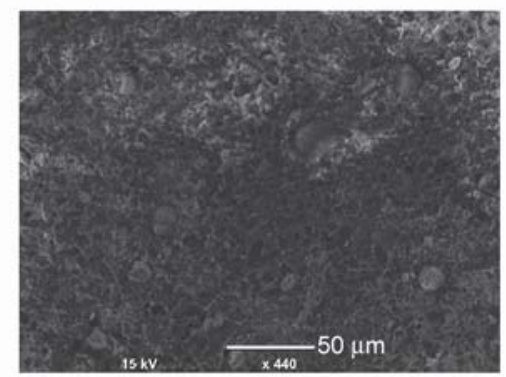

e)

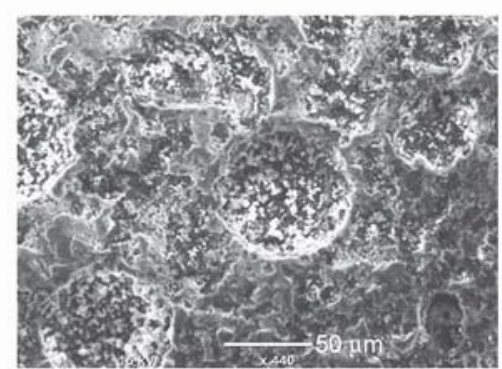

h)

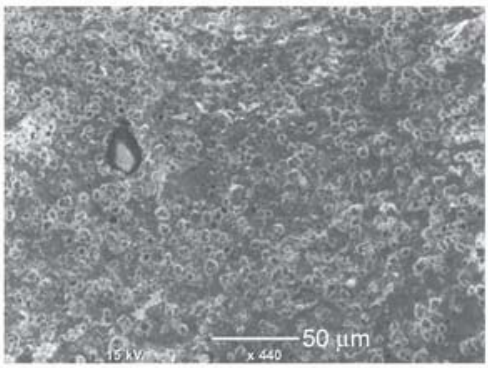

k)

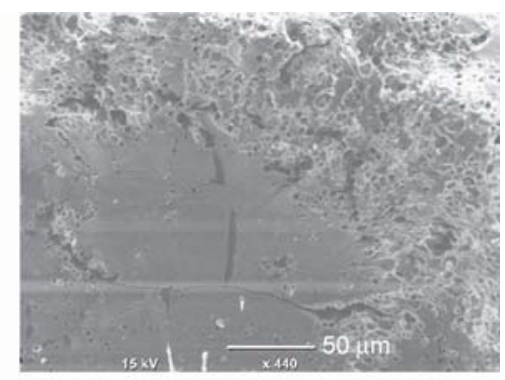

c)

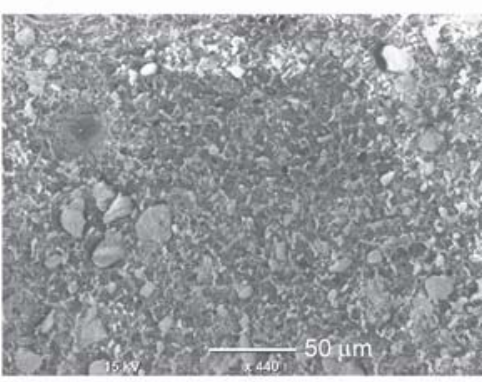

f)

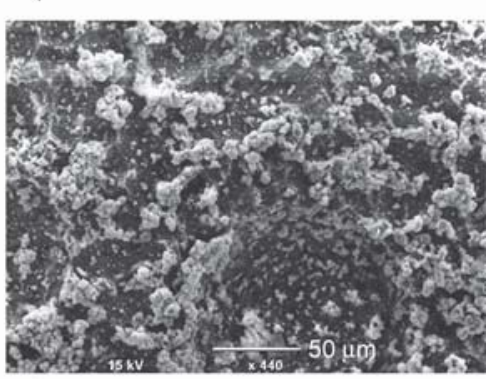

i)

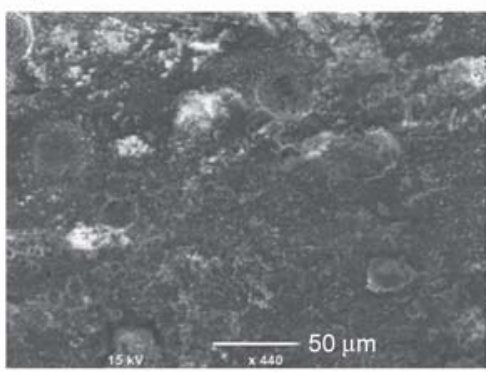

।)

Figure 2. SEM images of control epoxy coating at a) 0 day, b) 30 day, c) 45 day of exposure; EP/HNT d) 0 day, e) 30 day, f) 45 day of exposure; EP/TNT1 g) 0 day, h) 30 day, i) 45 day of exposure; EP/TNT2 j) 0 day, k) 30 day, l) 45 day of exposure

not clear in these composite coatings. The amount and nature of degraded product depends on the type of nanotubes used. In the case of both EP/TNT1 and EP/TNT2 coatings, the photo-catalytic degradation of epoxy matrix with $\mathrm{TiO}_{2}$ nanotubes are possible. This results in white degraded product on the surface. It is found that the white degraded products are denser and uniformly formed in EP/TNT1 coating when compared with EP/TNT2. This is mostly because the smaller size of TNT1 facilitates lower rate of encapsulation (loading) of epoxy monomer when compared with TNT2, which intern allows the existence of more bare $\mathrm{TiO}_{2}$ nanotube structures in
EP/TNT1 coating with their normal photo-catalytic activity. However, in EP/TNT2 coating the reduced photocatalytic activity of $\mathrm{TiO}_{2}$ nanotubes with sufficient encapsulation of epoxy monomer inside the tube cavity provides less amount of white degraded product on the surface.

Further confirmation of morphological finding were obtained from bright field optical profilometer images (Figure 3). Severe blistering of coating surface is evident for the control epoxy coating after 45 days of weathering exposure (Figure 2c). The blisters are formed by water absorption, which causes osmotic pressure effects in the coating during UV radiation 


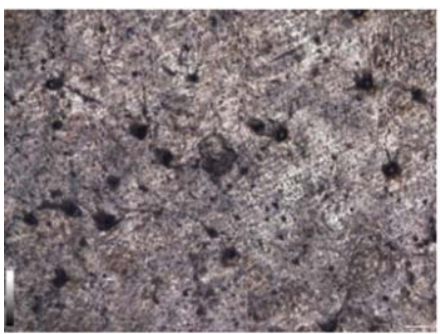

a)
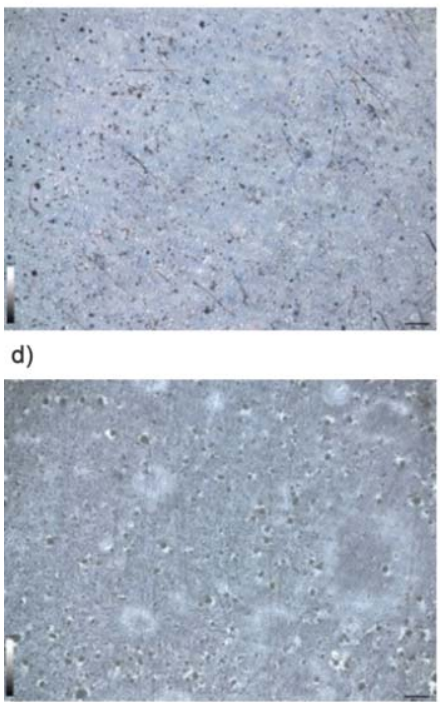

g)

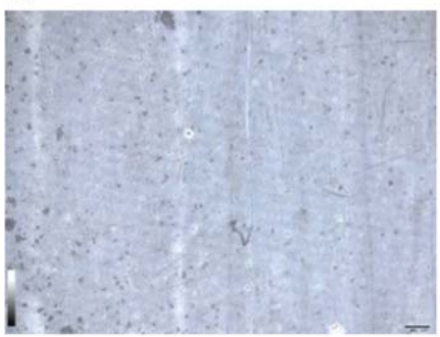

j)

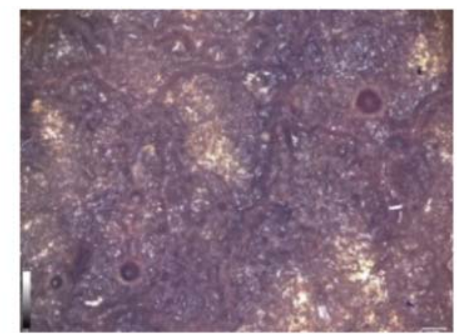

b)

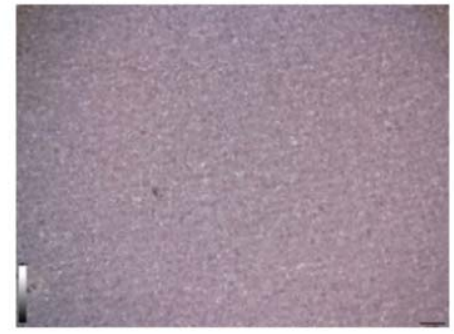

e)

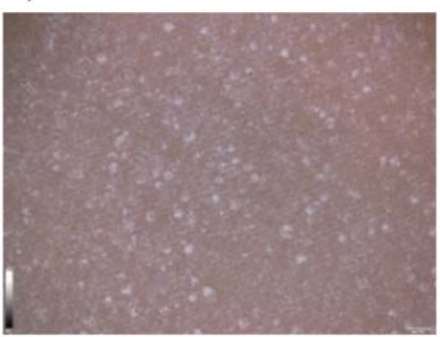

h)

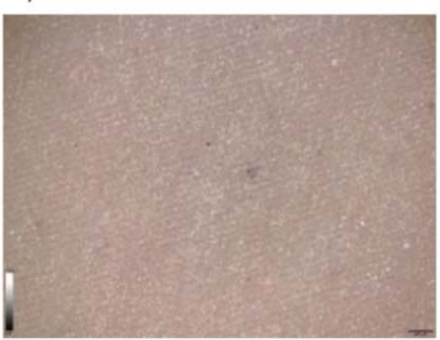

k)

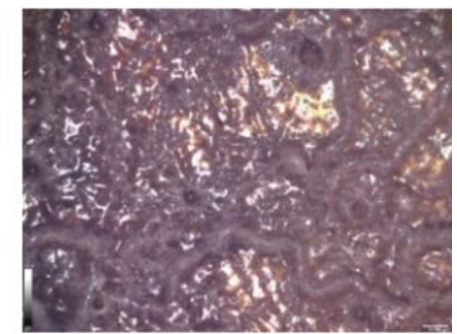

c)

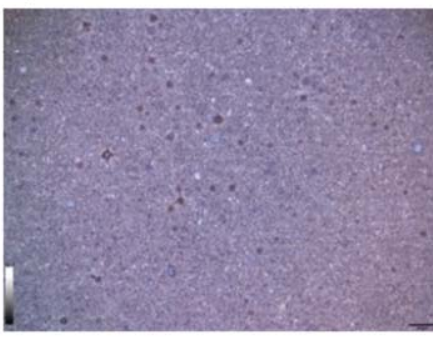

f)
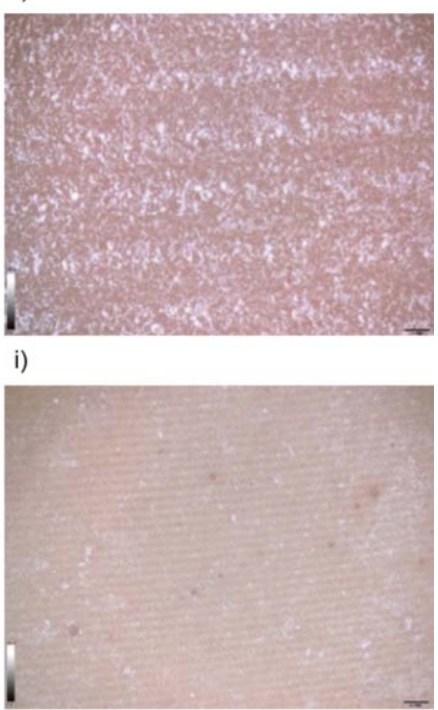

I)

Figure 3. Bright field optical images of control epoxy coating at a) 0 day, b) 30 day, c) 45 day of exposure; EP/HNT/Imeso; d) 0 day, e) 30 day, f) 45 day of exposure; EP/TNT1; g) 0 day, h) 30 day, i) 45 day of exposure; EP/TNT2; j) 0 day, k) 30 day, 1) 45 day of exposure

and water condensation alternating cycling [30]. The blisters are found as interconnected in the control coating surface as weathering exposure time increases. This blistering is absent in three composite coatings. Among the nanotube incorporated coatings, the quality of the surface is highly maintained in EP/TNT2 coating. The white degraded products uniformly formed in EP/TNT1 coating is also evident in optical images (Figure $3 \mathrm{~h}$ and $3 \mathrm{i}$ ).

\subsection{FTIR studies on degradation}

For studying the chemical changes during degradation of epoxy coating, the bands at $1510 \mathrm{~cm}^{-1}$ (benzene ring stretching), $3400 \mathrm{~cm}^{-1}$ (OH stretching), $2925 \mathrm{~cm}^{-1}$ $\left(\mathrm{CH}_{2}\right.$ stretching $)$ are considered. The change in FTIR spectra band at $1510 \mathrm{~cm}^{-1}$ in different coating at different exposure time is shown in Figure 4. A decrease in intensity of band at $1510 \mathrm{~cm}^{-1}$ indicates aromatic ring loss which signifies a chain scission process because these bands represent the chemical groups present in the main chains of the epoxy resin [31]. In control epoxy coating and EP/TNT1 coatings, the decrease in $1510 \mathrm{~cm}^{-1}$ evident the chain scission process. However, in EP/HNT and EP/TNT2 coatings, the decrease in band intensity was found to increase on further UV exposure days. Here, the possibility of exposure of epoxy monomer encapsulated inside both HNT and TNT2 during degradation process is higher than TNT1 and further cures with UV light (UV-curing) to create new chains. 

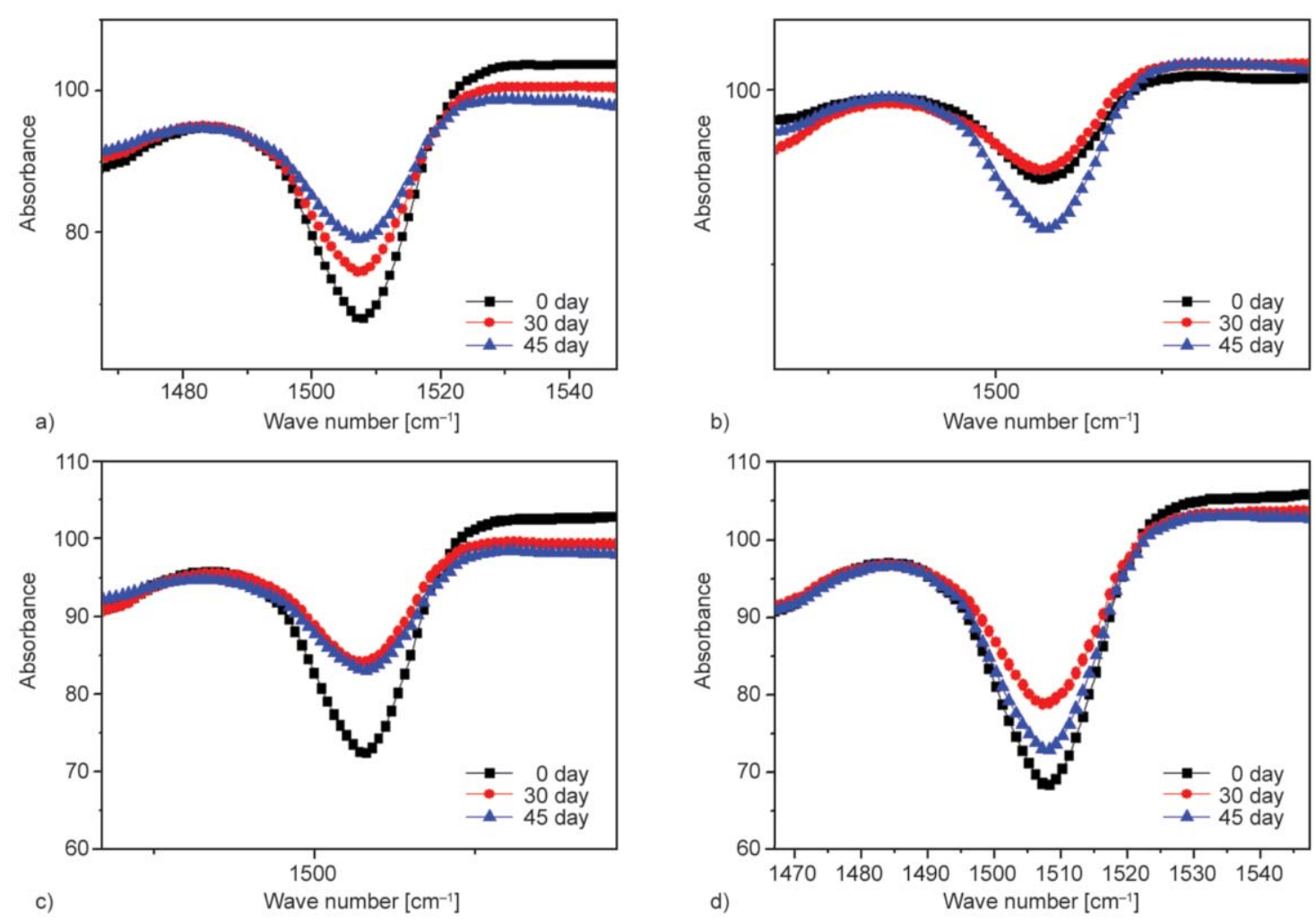

Figure 4. FTIR spectra showing the band at $1510 \mathrm{~cm}^{-1}$ of a) EP, b) EP/HNT, c) EP/TNT1 and d) EP/TNT2 at different weathering exposure time

A decrease of the $2925 \mathrm{~cm}^{-1}\left(\mathrm{CH}_{2}\right.$ stretching) band intensity represents a mass loss of the cured epoxy. While a mass loss in control epoxy is evident as shown in Figure 5, in EP/HNT coating an increase in $2925 \mathrm{~cm}^{-1}$ peak intensity represents a mass gain during weathering exposure. The possible reason for this mass gain is the hydroxyl group on the internal aluminol surface of the halloysite tubes initiates the UV curing of the unreacted epoxy groups in the coating. The hydroxyl group act as chain transfer agents, similar to the action of diols in the cationic ring opening polymerisation of epoxy groups [32]. There is no apparent change in intensity of $2925 \mathrm{~cm}^{-1}$ for $\mathrm{EP} / \mathrm{TNT} 1$ and EP/TNT2 is detected.

\subsection{Surface roughness of exposed coatings}

Surface roughness of the different coating samples as a function of weathering time is shown in Figure 6. From Figure 6, it can be seen that the roughness of the control coating is increased by the addition of the nanotubes. The highest increment in roughness was achieved with the incorporation of HNT and TNT2. The higher surface area of the TNT1 make it uniformly dispersed in the matrix without agglomerates compared to HNT and TNT2. A similar study was previously reported for polyurethane coating containing silane treated $\mathrm{TiO}_{2}$ nanoparticles [33]. They found that the aggregation of nanoparticles increased the surface roughness.

The extensive degradation of the control epoxy coating causes sudden increase in the surface roughness with exposure time. However, the behavior of selfhealing coatings were different from the control coating. For EP/TNT1, the surface roughness slightly decreased with exposure time. This implies the repairing process going on the surface of the coating during weathering along with the prevention of coating degradation even after 45 days. In the case of EP/HNT and EP/TNT2, the surface roughness dropped till 30 days of exposure and after that, it started to increase. This indicates that the large tube diameter of HNT and TNT2 when compared with TNT1 allows fast release of epoxy monomer and fast recovery, after 30 days it starts to degrade.

\section{Conclusions}

The long term stability of self-healing epoxy coatings with inorganic nanotubes as healing agent reservoirs were studied. $\mathrm{TiO}_{2}$ nanotubes with two different tube diameters and Hallyosite nanotubes were used as epoxy monomer reservoirs in these coatings. $\mathrm{TiO}_{2}$ nanotubes with higher surface area and lower 

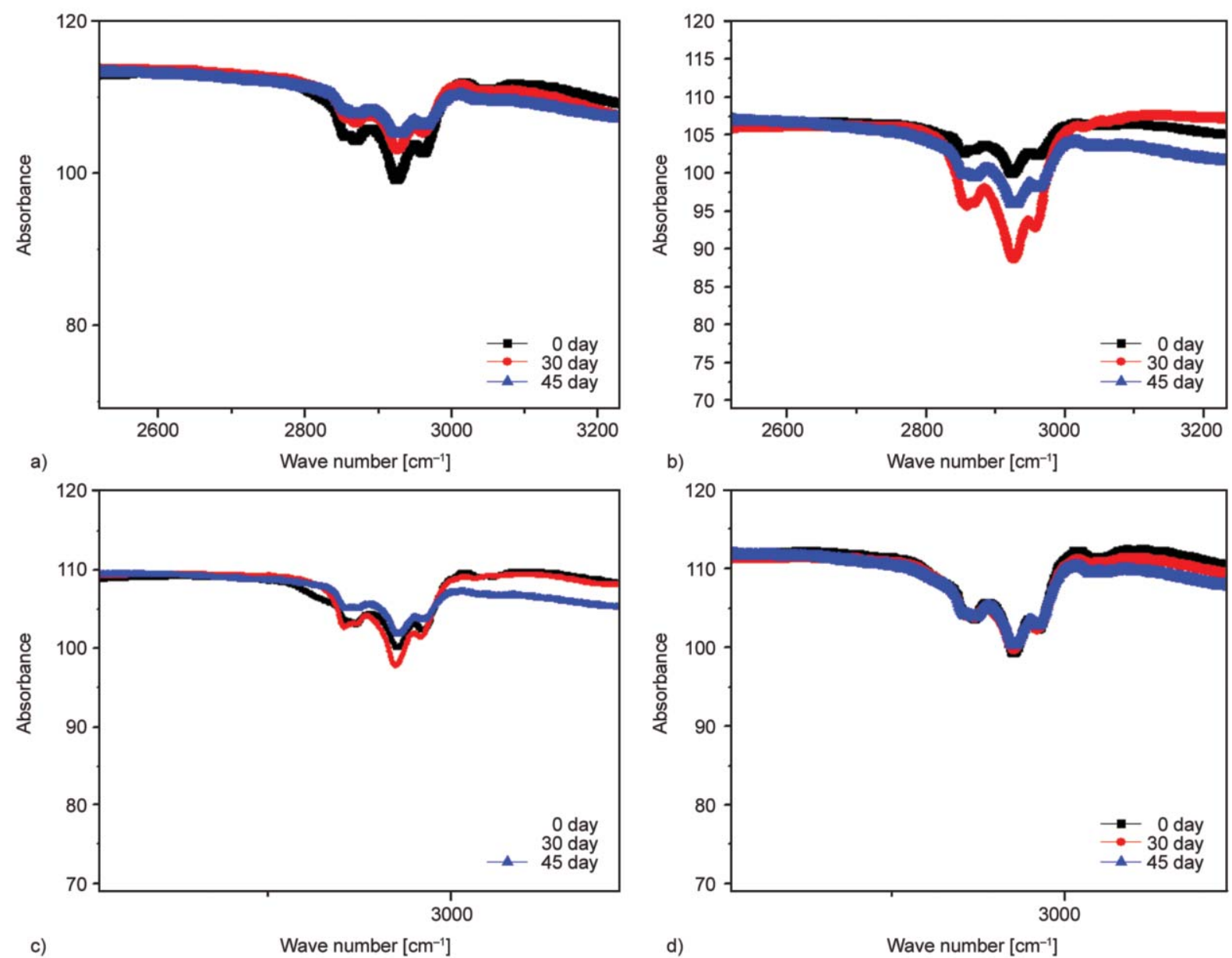

Figure 5. FTIR spectra showing the band at $2925 \mathrm{~cm}^{-1}$ of a) control epoxy, b) EP/HNT, c) EP/TNT1 and d) EP/ TNT2 at different weathering exposure time

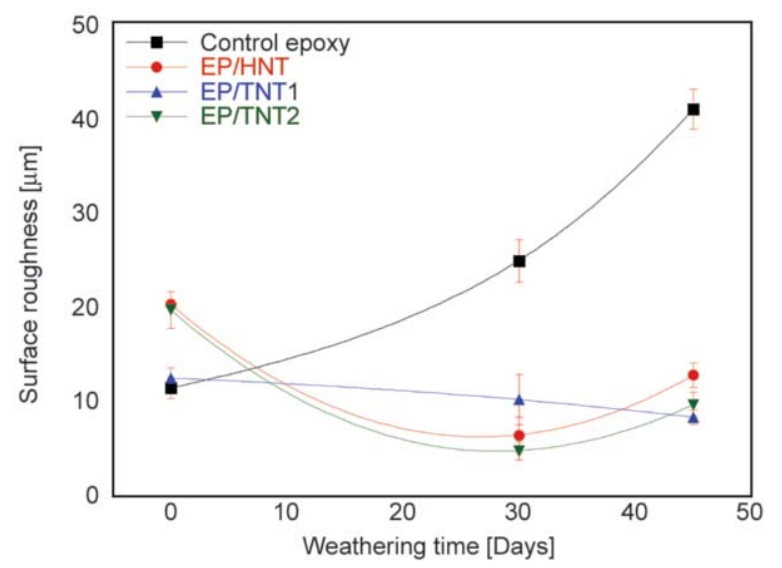

Figure 6. Variation of surface roughness of coatings as a function of weathering exposure time

tube diameter (TNT1) were found to be superior in enhancing the corrosion resistance of the coatings. The percentage recovery of corrosion resistance with respect to control coating interms of low frequecny impedance were $30.98,64.16$ and $105 \%$ for EP/HNT, EP/TNT1 and EP/TNT2 coatings respectively. The $\mathrm{TiO}_{2}$ nanotubes with lower surface area and higher tube diameter (TNT2) better enhanced the self-healing ability. The stability of coatings upon exposure to weathering environment were compared with SEM, optical images, FTIR and surface roughness. The major conclusions are listed below:

- The reduced photocatalytic activity of TNT2 due to the sufficient encapsulation of epoxy monomer inside the tube cavity provided less amount of white degraded product on the coating surface after 45 days of weathering.

- Due to the higher possibility of exposure of epoxy monomer encapsulated inside both HNT and TNT2 compared with TNT1 during degradation process, cure with UV light (UV-curing) to create new chains to recover the weathering damage.

- Repairing process in EP/TNT1 coating is going at the surface during weathering along with the prevention of coating degradation even after 45 days. The large tube diameter of HNT and TNT2 when compared with TNT1 allows fast release of epoxy monomer and fast recovery and further it starts to degrade after 45 days. 


\section{Acknowledgements}

This manuscript was made possible by PDRA grant \# PDRA1-1216-13014 from the Qatar National Research Fund (a member of Qatar Foundation). The findings achieved herein are solely the responsibility of the authors.

\section{References}

[1] Fayyad E. M., Almaadeed M. A., Jones A., Abdullah A. M.: Evaluation techniques for the corrosion resistance of self-healing coatings. International Journal of Electrochemical Science, 9, 4989-5011 (2014).

[2] Fayyad E. M., Almaadeed M. A., Jones A.: Encapsulation of tung oil for self-healing coatings in corrosion applications. Science of Advanced Materials, 7, 2628 2638 (2015).

https://doi.org/10.1166/sam.2015.2583

[3] Ahmadi B., Kassiriha M., Khodabakhshi K., Mafi E. R.: Effect of nano layered silicates on automotive polyurethane refinish clear coat. Progress in Organic Coatings, 60, 99-104 (2007).

https://doi.org/10.1016/j.porgcoat.2007.07.008

[4] Kowalczyk K., Spychaj T.: Epoxy coatings with modified montmorillonites. Progress in Organic Coatings, 62, 425-429 (2008). https://doi.org/10.1016/j.porgcoat.2008.03.001

[5] Zaarei D., Sarabi A. A., Sharif F., Kassiriha S. M., Gudarzi M. M.: Preparation and evaluation of epoxy-clay nanocomposite coatings for corrosion protection. International Journal of Nanoscience and Nanotechnology, 7, 126-136 (2010).

[6] Javidparvar A. A., Ramezanzadeh B., Ghasemi E.: Effects of surface morphology and treatment of iron oxide nanoparticles on the mechanical properties of an epoxy coating. Progress in Organic Coatings, 90, 10-20 (2016). https://doi.org/10.1016/j.porgcoat.2015.09.018

[7] Conradi M., Kocijan A., Zorko M., Verpoest I.: Damage resistance and anticorrosion properties of nanosilicafilled epoxy-resin composite coatings. Progress in Organic Coatings, 80, 20-26 (2015).

https://doi.org/10.1016/j.porgcoat.2014.11.011

[8] Maganty S., Roma M. P. C., Meschter S. J., Starkey D., Gomez M., Edwards D. G., Ekin A., Elsken K., Cho J.: Enhanced mechanical properties of polyurethane composite coatings through nanosilica addition. Progress in Organic Coatings, 90, 243-251 (2016).

https://doi.org/10.1016/j.porgcoat.2015.10.016

[9] Rashvand M., Ranjbar Z., Rastegar S.: Preserving anticorrosion properties of epoxy based coatings simultaneously exposed to humidity and UV-radiation using nano zinc oxide. Journal of the Electrochemical Society, 159, 129-132 (2012).

https://doi.org/10.1149/2.093203jes

[10] Rajagopalan N., Khanna A. S.: Effect of nano-ZnO in lowering yellowing of aliphatic amine-cured DGEBAbased epoxy coatings on UV exposure. International Journal of Scientific and Research Publications, 3, 111 (2013).
[11] Kowalczyk K., Łuczka K., Grzmil B., Spychaj T.: Anticorrosive $2 \mathrm{~K}$ polyurethane paints based on nano- and microphosphates with high dispersing additive content. Progress in Organic Coatings, 76, 1088-1094 (2013). https://doi.org/10.1016/j.porgcoat.2013.03.003

[12] Chang C-H., Huang T-C., Peng C-W., Yeh T-C., Lu H-I., Hung W-I., Weng C-J., Yang T-I., Yeh J-M.: Novel anticorrosion coatings prepared from polyaniline/graphene composites. Carbon, 50, 5044-5051 (2012). https://doi.org/10.1016/j.carbon.2012.06.043

[13] Naik R. B., Jagtap S. B., Ratna D.: Effect of carbon nanofillers on anticorrosive and physico-mechanical properties of hyperbranched urethane alkyd coatings. Progress in Organic Coatings, 87, 28-35 (2015).

https://doi.org/10.1016/j.porgcoat.2015.05.001

[14] Ghasemi-Kahrizsangi A., Shariatpanahi H., Neshati J., Akbarinezhad E.: Degradation of modified carbon black/ epoxy nanocomposite coatings under ultraviolet exposure. Applied Surface Science, 353, 530-539 (2015). https://doi.org/10.1016/j.apsusc.2015.06.029

[15] Vijayan P. P., Al-Maadeed M. A.: 'Containers' for selfhealing epoxy composites and coating: Trends and advances. Express Polymer Letters, 10, 506-524 (2016). https://doi.org/10.3144/expresspolymlett.2016.48

[16] He X., Shi X.: Self-repairing coating for corrosion protection of aluminum alloys. Progress in Organic Coatings, 65, 37-43 (2009). https://doi.org/10.1016/j.porgcoat.2008.09.003

[17] Lamaka S. V., Zheludkevich M. L., Yasakau K. A., Serra R., Poznyak S. K., Ferreira M. G. S.: Nanoporous titania interlayer as reservoir of corrosion inhibitors for coatings with self-healing ability. Progress in Organic Coatings, 58, 127-135 (2007).

https://doi.org/10.1016/j.porgcoat.2006.08.029

[18] Shchukin D. G., Zheludkevich M., Yasakau K., Lamaka S., Ferreira M. G., Möhwald H.: Layer-by-layer assembled nanocontainers for self-healing corrosion protection. Advanced Materials, 18, 1672-1678 (2006). https://doi.org/10.1002/adma.200502053

[19] Zheludkevich M. L., Serra R., Montemor M. F., Ferreira M. G.: Oxide nanoparticle reservoirs for storage and prolonged release of the corrosion inhibitors. Electrochemistry Communications, 7, 836-840 (2005). https://doi.org/10.1016/j.elecom.2005.04.039

[20] Qiao Y., Li W., Wang G., Zhang X., Cao N.: Application of ordered mesoporous silica nanocontainers in an anticorrosive epoxy coating on a magnesium alloy surface. RSC Advances, 5, 47778-47787 (2015). https://doi.org/10.1039/C5RA05266A

[21] Borisova D., Möhwald H., Shchukin D. G.: Mesoporous silica nanoparticles for active corrosion protection. ACS Nano, 5, 1939-1946 (2011). https://doi.org/10.1021/nn102871v

[22] Arunchandran C., Ramya S., George R. P., Mudali U. $\mathrm{K}$.: Self-healing corrosion resistive coatings based on inhibitor loaded $\mathrm{TiO}_{2}$ nanocontainers. Journal of the Electrochemical Society, 159, 552-559 (2012). https://doi.org/10.1149/2.020212jes 
[23] Balaskas A. C., Kartsonakis I. A., Tziveleka L-A., Kordas G. C.: Improvement of anti-corrosive properties of epoxy-coated AA 2024-T3 with $\mathrm{TiO}_{2}$ nanocontainers loaded with 8-hydroxyquinoline. Progress in Organic Coatings, 74, 418-426 (2012).

https://doi.org/10.1016/j.porgcoat.2012.01.005

[24] Liu Y., Wang L., Zhang Z. C., Zhang K., Liu G.: A hollow porous $\mathrm{Mn}_{2} \mathrm{O}_{3}$ microcontainer for encapsulation and release of corrosion inhibitors. ECS Electrochemistry Letters, 2, 39-42 (2013).

https://doi.org/10.1149/2.003310eel

[25] Vijayan P. P., El-Gawady Y. M. H., Al-Maadeed M. A. S.: Halloysite nanotube as multifunctional component in epoxy protective coating. ACS Industrial Engineering and Chemistry Research, 55, 11186-11192 (2016). https://doi.org/10.1021/acs.iecr.6b02736

[26] Vijayan P. P., Al-Maadeed M. A. S.: $\mathrm{TiO}_{2}$ nanotubes and mesoporous silica as containers in self-healing epoxy coatings. Scientific Reports, 6, 38812/1-38812/9 (2016). https://doi.org/10.1038/srep38812

[27] Du G. H., Chen Q., Che R. C., Yuan Z. Y., Peng L-M.: Preparation and structure analysis of titanium oxide nanotubes. Applied Physics Letters, 79, 3702-3704 (2001).

https://doi.org/10.1063/1.1423403

[28] Thielemann J. P., Girgsdies F., Schlögl R., Hess C.: Pore structure and surface area of silica SBA-15: Influence of washing and scale-up. Beilstein Journal of Nanotechnology, 2, 110-118 (2011).

https://doi.org/10.3762/bjnano.2.13
[29] Samadzadeh M., Hatami Boura S., Peikari M., Ashrafi A., Kasiriha M.: Tung oil: An autonomous repairing agent for self-healing epoxy coatings. Progress in Organic Coatings, 70, 383-387 (2011). https://doi.org/10.1016/j.porgcoat.2010.08.017

[30] Yang X. F., Tallman D. E., Bierwagen G. P., Croll S. G., Rohlik S.: Blistering and degradation of polyurethane coatings under different accelerated weathering tests. Polymer Degradation and Stability, 77, 103-109 (2002). https://doi.org/10.1016/S0141-3910(02)00085-X

[31] Gu X., Nguyen T., Oudina M., Martin D., Kidah B., Jasmin J., Rezig A., Sung L., Byrd E., Martin J. W., Ho D. L., Jean Y. C.: Microstructure and morphology of aminecured epoxy coatings before and after outdoor exposures - an AFM study. Journal of Ccoatings Technology and Research, 2, 547-556 (2005).

https://doi.org/10.1007/s11998-005-0014-x

[32] Ceccia S., Turcato E. A., Maffettone P. L., Bongiovanni R.: Nanocomposite UV-cured coatings: Organoclay intercalation by an epoxy resin. Progress in Organic Coatings, 63, 110-115 (2008). https://doi.org/10.1016/j.porgcoat.2008.04.012

[33] Mirabedini S. M., Sabzi M., Zohuriaan-Mehr J., Atai M., Behzadnasab M.: Weathering performance of the polyurethane nanocomposite coatings containing silane treated $\mathrm{TiO}_{2}$ nanoparticles. Applied Surface Science, 257, 4196-4203 (2011).

https://doi.org/10.1016/j.apsusc.2010.12.020 